\title{
Head and neck cutaneous basal cell carcinoma: A challenging entity of ENT surgeons
}

\author{
Aikaterini D Lianou ${ }^{1,}{ }^{*}$, Athina Zarachi ${ }^{1}$, Konstantinos Tsimos ${ }^{2}$, Alkistis Tsikou ${ }^{1}$, Konstantina Mparka ${ }^{1}$ and \\ Ioannis Kastanioudakis 1 \\ ${ }^{1}$ Department of Otorhinolaryngology, Head and Neck Surgery, Faculty of Medicine, School of Health Sciences, University of \\ Ioannina, Ioannina, Greece. \\ ${ }^{2}$ Department of Cardiology, School of Health Sciences, University of Ioannina, Ioannina, Greece.
}

International Journal of Science and Research Archive, 2022, 05(01), 140-142

Publication history: Received on 17 January 2022; revised on 24 February 2022; accepted on 26 February 2022

Article DOI: https://doi.org/10.30574/ijsra.2022.5.1.0033

\begin{abstract}
Otorhinolaryngology head and neck (ENT) surgeons are often challenged in their daily practice with patients presenting cutaneous cancer. Cutaneous basal cell carcinoma ( $\mathrm{CBCC}$ ) is the most common cancer diagnosed in human population, with $80 \%$ occurring in the head and the neck. We present the case of a 56-year-old male patient with an extensive lesion on the right zygomatic area that examined in the outpatient ENT Department of our hospital. A surgical excision of the lesion was performed, under local anesthesia and then we used a superficial based neck flap to reconstruct the defect. The final postoperative result was satisfactory. The histological examination revealed a basal cell carcinoma.
\end{abstract}

Keywords: Neck flap; Skin lesion; Basal cell carcinoma; Reconstruction

\section{Introduction}

Cutaneous basal cell carcinoma ( $\mathrm{cBCC}$ ) is the most common malignancy diagnosed in the human population, accounting for $70-80 \%$ of all skin malignancies in fair-skin people and has an increasing incidence [1]. cBCC is mainly found in the head and neck at a rate of $80 \%$ and surgical removal remains the main method of treatment, particularly when diagnosed early [2,3]. It is rarely metastasizes and has a low mortality rate, while its morbidity is affected by local invasion and destruction, especially in the face, where function and aesthetics are major issues [4]. This makes cBCC an important issue for head and neck otolaryngology surgeons who need to be knowledgeable and dedicated to its management, as the mainstay of treatment is still surgery. We present the case of a man with a BCC of the right zygomatic area with extension to the medial canthus that removed using a surgical excision. The reconstruction was performed using a neck flap.

\section{Case report}

A 56-year-old male patient examined in the outpatient ENT Department of our hospital, because of a lesion on the right zygomatic area, for about two years. According to the patient's medical history, at the last two weeks the lesion has shown a rapid increase in size after injury with the patient's nails. The patient visited the emergency room (ER) of a provincial hospital. ENT doctor was not on duty and the general surgeons treated it as an abscess, so they opened it and drained it. The patient received antibiotics for ten days and after that he visited our outpatient ENT Department, where extensive lesion was found in the zygomatic area, extending to the medial canthus (Figure 1). The patient has a chronic renal failure undergoing dialysis and he receives antihypertensive and anticoagulant medication. Through clinical examination, we did not reveal any other pathological findings. No lymph nodes were found in the neck area.

\footnotetext{
${ }^{*}$ Corresponding author: Aikaterini D Lianou

Department of Otorhinolaryngology, Head and Neck Surgery, Faculty of Medicine, School of Health Sciences, University of Ioannina, Ioannina, Greece. 
After a preoperative evaluation, included hematological and cardiological tests, a surgical excision of the lesion was performed, under local anesthesia. A resection line was drawn around the lesion. A second resection line was drawn in the right neck area, to be used for the reconstructive flap. Neutralized lidocaine with epinephrine used for local anesthesia. The lesion removed through an excision followed by haemostasis with bipolar diathermy.

Biopsy was fixed in formalin and sent to a referral laboratory for histological preparation and examination. We used thin skin sutures to fix the skin. We used a pressure bandage to prevent the occurrence of a hematoma that remained in place for 5 days.

Five days later, the most stitches removed safely, as the patient followed the aftercare instructions (Figure 2). The rest stitches removed 5 days later. Both surgical incisions heal, so the final postoperative result was satisfactory (Figure 3, Figure 4). The histological examination result revealed a basal cell carcinoma, as expected.

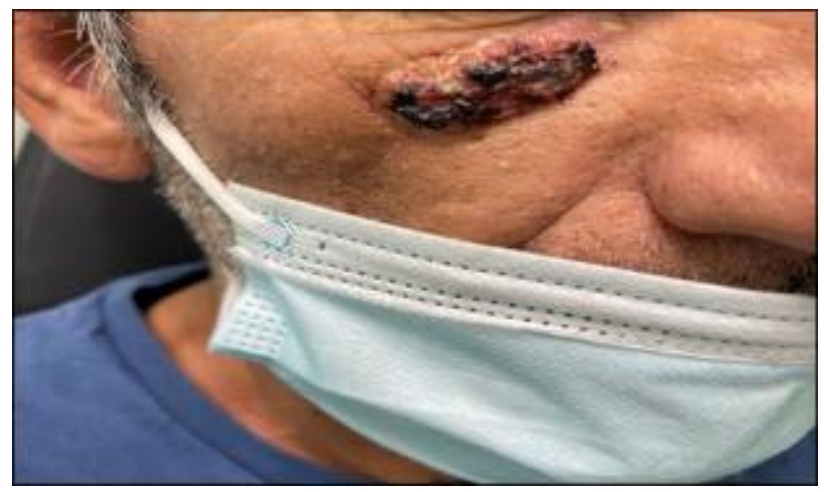

Figure 1 Extensive lesion on the zygomatic area, extending to the medial canthus

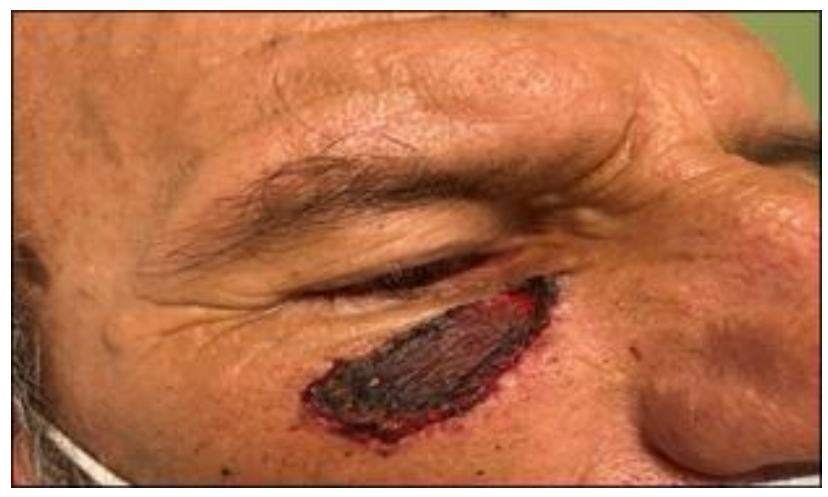

Figure 3 Postoperative result, after the stitches removal

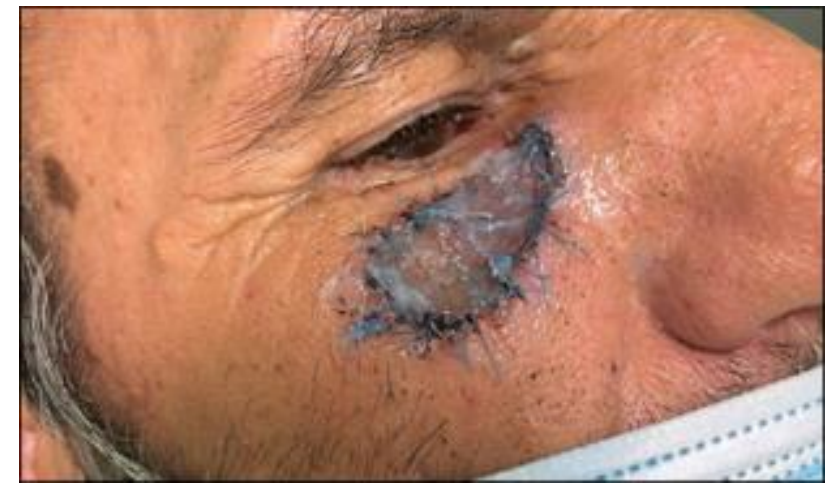

Figure 2 Postoperative result, 5 days after the reconstruction

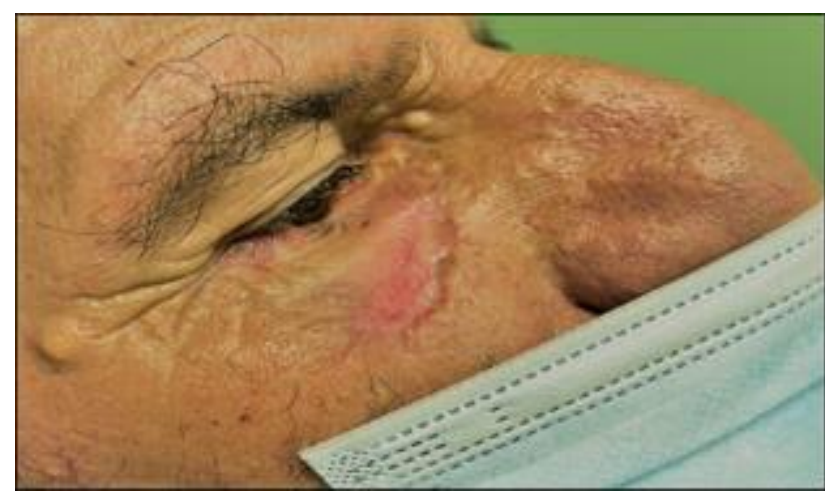

Figure 4 Final postoperative result, after surgical incisions heal

\section{Discussion}

Basal cell carcinoma is one of the commonest skin cancers of the head and neck area. Its localization can be anywhere and many techniques proposed for its surgical excision [5]. Surgical removal of the entire lesion with clear margins is standard treatment for cBCC [6]. Surgical excision is followed by primary closure or reconstruction with tissue flaps, skin grafts, or healing by secondary intention [7]. In some patients, the surgical wound is closed after definitive histopathological diagnosis $[8,9,10]$. We used a superficial based neck flap to reconstruct the defect of a 56-year-old man. We achieved complete coverage of the deficit remained after surgical excision of the lesion. The graft did not reject and the perfusion was effective.

\section{Conclusion}

The cBCC is, and will continue to be, a major public health problem due to its increasing frequency, causing an increased financial burden on healthcare systems. CBCCs are mainly found in the head and neck, making these lesions very 
important for ENT surgeons who need to be clinically competent and know how to manage them, as the main method of treatment is surgery.

\section{Compliance with ethical standards}

\section{Disclosure of conflict of interest}

The authors declare no conflicts of interest regarding the publication of this paper.

\section{Statement of informed consent}

Informed consent was obtained from all individual participants included in the study.

\section{References}

[1] António Castanheira, Paula Boaventura, Manuel Pais Clemente,Paula Soares, Alberto Mota, José Manuel Lopes. Head and neck cutaneous basal cell carcinoma: what should the otorhinolaryngology head and neck surgeon care about? ACTA OTORHINOLARYNGOLOGICA ITALICA 2020; 40: 5-18.

[2] Chinem VP, Miot HA. Epidemiology of basal cell carcinoma. A Bras Dermatol. 2011; 86: 292-305.

[3] Rubin AI, Chen EH, Ratner D. Basal-cell carcinoma. N Engl J Med. 2005; 353: 2262-9.

[4] Trakatelli M, Morton C, Nagore E, et al. Guidelines on the treatment of basal cell carcinoma. [Internet]. Berlin: European Dermatology Forum. 2012. Available from: http://www.euroderm.org/edf/index.php/edfguidelines/category/5-guidelines-miscellaneous.

[5] Bichakjian CK, Olencki T, Aasi SZ, et al. Basal cell skin cancer, version 1.2016, NCCN clinical practice guidelines in oncology. J Natl Compr Canc Netw. 2016; 14: 574-97.

[6] Silverman MK, Kopf AW, Bart RS, et al. Recurrence rates of treated basal cell carcinomas. Part 3: surgical excision. J Dermatol Surg Oncol. 1992; 18: 471-6.

[7] Silverman MK, Kopf AW, Grin CM, et al. Recurrence rates of treated basal cell carcinomas. Part 2: curettageelectrodesiccation. J Dermatol Surg Oncol. 1991; 17: 720-6.

[8] Andrade P, Brites MM, Vieira R, et al. Epidemiology of basal cell carcinomas and squamous cell carcinomas in a Department of Dermatology: a 5 year review. A Bras Dermatol. 2012; 87: 212-9.

[9] Trakatelli M, Morton C, Nagore E, et al. Update of the European guidelines for basal cell carcinoma management. Eur J Dermatol. 2014; 24: 312-29.

[10] Christenson LJ, Borrowman TA, Vachon CM, et al. Incidence of basal cell and squamous cell carcinomas in a population younger than 40 years. JAMA. 2005; 294: 681-90. 